\title{
PERBEDAAN TINGKAT DEPRESI PADA LANSIA SEBELUM DAN SESUDAH DIBERIKAN TERAPI MUSIK KERONCONG
}

\author{
Differences in depression Levels in the elderly before and after being given keroncong \\ music therapy
}

\author{
Roufuddin $^{1}$, Nurul Masruroh ${ }^{2}$, Virki Widoyanti ${ }^{3}$ \\ ${ }^{1,2,3}$ Prodi Keperawatan Stikes ABI Surabaya
}

\author{
Alamat Korespondensi : Prodi Keperawatan STIKES ABI \\ Jl. Pumpungan III No. 29 Sukolilo Surabaya \\ Email : roufuddin20@gmail.com
}

\begin{abstract}
ABSTRAK
Memasuki usia tua akan mengalami kemunduran baik secara fisik, psikologis, maupun biologis. Kemunduran psikologis yang sering dijumpai pada lansia salah satunya adalah depresi. Salah satu terapi non farmakologis yang dapat digunakan untuk menurunkan tingkat depresi lansia adalah menggunakan terapi musik keroncong. Tujuan penelitian ini adalah untuk mengetahui perbedaan tingkat depresi pada lansia sebelum dan sesudah diberikan terapi musik keroncong di UPTD Griya Werdha Jambangan Surabaya.

Metode yang digunakan adalah penelitian analitik pre experimental pre test post test design. Populasinya sebanyak 40 orang lansia dengan sampel sebanyak 36 responden di UPTD Griya Werdha Jambangan Surabaya dengan teknik pengambilan sampel menggunakan purposive sampling. Pengambilan data menggunakan kuesioner. Analisa data menggunakan uji statistik Wilcoxon RankTest.

Hasil penelitian didapatkan bahwa ada perbedaan tingkat depresi pada lansia sebelum dan sesudah diberikan terapi musik keroncong di UPTD Griya Werdha Jambangan Surabaya denganangkasignifikan $\mathrm{p}$ value $=0,000$ lebih rendah dari $\alpha=0,05 \quad(\mathrm{p}<\alpha)$. Sebelum perlakuan, sebagian besar lansia mengalami tingkat depresi ringan sebanyak 11 responden $(30,6 \%)$ dan setelah perlakuan sebagian besar lansia mengalami tingkat depresi ringan sebanyak 16 responden(44,4\%).

Ada perbedaan tingkat depresi pada lansia sebelum dan sesudah diberikan terapi musik keroncong di UPTD Griya Werdha Jambangan Surabaya. Untuk itu, terapi musik dapat menjadi pilihan untuk menurunkan skor depresi pada lansia di UPTD Griya Werdha Jambangan Surabaya.
\end{abstract}

Kata kunci : depresi, lansia, terapi musik keroncong

\section{ABSTRACT}

Coming to an old age a person will experience physical, psychological, and biological setbacks. Psychological deterioration which is often found in the elderly is depression. One of the non-pharmacological therapies that can be applied to reduce depression levels in the elderly is touse keroncong music therapy. The purpose of this study was to determine the differences in depressionlevels in the elderly before and after being given keroncong music therapy at UPTD Griya Werdha Jambangan Surabaya.

The method used was an analytical pre-experimental research with pre test post test design. The population is 40 elderly with 36 samples in the UPTD Griya Werdha Jambangan Surabaya taken using purposive sampling techniques.The data was taken using aquestionnaire.Data analysis used the Wilcoxon Rank Test statisticalt est.

From the results of the study, it was found that there was a difference in the levels of depressionintheelderlybeforeandafterbeinggivenkeroncongmusictherapyatUPTDGriyaWerdhaJam bangan Surabaya with a significant valueof $=0.0001$ lower than $\alpha=0.05(p<\alpha$.). Before thetherapy or treatment, most of the elderly experienced depression levels with as many as 11 respondents(30.6\%)andafterthetreatmentmostofthemexperienceddepressionlevelwithasmanyas 16re spondents $(44.4 \%)$. 
It could be concluded that there was a difference in levels of depression in the elderly before andafter being given keroncong music therapy at UPTD Griya Werdha Jambangan Surabaya. For thisreason, music therapy can be an option to decrease the depression level in the elderly at UPTD Griya Werdha Jambangan Surabaya.

Keywords : elderly, depression, keroncong music therapy

\section{PENDAHULUAN}

Memasuki usia tua akan mengalami kemunduran baik secara fisik, psikologis, maupun biologis. Kemunduran psikologis yang sering dijumpai pada lansia antara lain perasaan tidak berguna, mudah sedih, insomnia, stres depresi, ansietas, demensia (Livana et al., 2018). Depresi merupakan penyakit mental yang paling sering muncul pada pasien berusia di atas 60 tahun.

Menurut data WHO (World Health Organization) tahun 2014 diseluruh dunia jumlah orang lanjut usia diperkirakan sebanyak 629 juta dengan usia rata-rata 60 tahun dan diperkirakan pada tahun 2025 akan mencapai 1,2 milyar. Prevalensi depresi pada lanjut usia di seluruh dunia pada tahun 2014 berkisar 13,5\% dari seluruh jumlah lanjut usia dengan perbandingan wanita sebanyak $8,4 \%$ dan pria sebanyak $5,1 \%$ (WHO, 2014).

Berdasarkan data Depkes RI tahun 2014 di Indonesia prevalensi lanjut usia sebanyak 20.893.000 jiwa dengan jumlah lanjut usia yang mengalami depresi ringan sampai berat sebanyak 32\% (Depkes RI, 2014). Data Provinsi Jawa Timur didapatkan, penduduk lanjut usia pada tahun 2014 diperkirakan mencapai angka 10,96\% dan tahun 2015 diperkirakan mencapai angka $11,5 \%$ dan hingga 2020 akan meningkat menjadi 13,5\%.

Data di Kota Surabaya didapatkan jumlah penduduk lanjut usia tahun 2014 mencapai 350.000 jiwa (13\%) dari total jumlah penduduk di Surabaya (BPS Kota Surabaya, 2014). Dari hasil studi pendahuluan pada tanggal 16 januari 2020 di UPTD Griya Werdha Jambangan Surabaya, jumlah semua lansia sebanyak 154 , jumlah lanisa yang mengalami depresi sebanyak 50 orang.

Gangguan depresi terjadi akibat dari perubahan-perubahan yang dialami lanjut usia sebagai faktor dari proses penuaan. Neurotransmiter yang terkait dengan patologi depresi adalah serotonin dan epineprin. Penurunan serotonin dapat mencetuskan depresi (Irawan.H, 2013). Sekitar tiga puluh neurotransmiter telah diketahui dan tiga di antaranya mempengaruhi terjadinya depresi, yaitu serotonin, norepinefrin, dan dopamine. Secara umum ketiga neurotransmiter berperan dalam mengatur emosi. Dampak dari depresi pada lansia akan menurunkan sistem imun yang akan menyebabkan lansia mudah terkena berbagai macam penyakit. Yang pada akhirnya akan menyebabkan kematian pada lansia. Depresi yang tidak ditangani bertahun-tahun dapat mengakibatkan kulaitas hidup yang buruk, kesulitan fungsi sosial, fisik, meningkatnya mortalitas akibat bunuh diri (Maryam, 2008).

Penatalaksanaan depresi dapat dilakukan dengan cara terapi farmakologi dan non farmakologi. Pada umumnya, tata laksana terapi farmakologi hanya menggunakan obat antidepresan contohnya monoamine oxidase inhibitors (MAOI), selective serotonin reuptake inhibitors (SSRI), dan tricyclic antidepressant (TSA), tetapi obat hanya mengurangi gejala, dan menimbulkan efek samping, diantaranya gangguan pencernaan dan kardiovaskuler (Abdul Muhith, 2016). Selain obat anti depresan, psikoterapi (talk theraphy) memiliki peranan penting dalam mengobati berbagai jenis depresi. Psikoterapi dilakukan oleh psikiater, psikolog terlatih, pekerja sosial, atau konselor.

Cara alternatif untuk menghindari efek samping obat antidepresan dalam mengatasi depresi dapat dilakukan dengan terapi non- farmakologi, di antaranya adalah dengan pendekatan psikodinamik, pendekatan perilaku belajar, pendekatan kognitif, dan dengan pendekatan humanistik eksistensial. Salah satu cara yang paling menarik untuk dilakukan adalah pendekatan psikodinamik, karena pendekatan ini tidak hanya menghilangkan gejala, tetapi juga memiliki manfaat untuk mengatasi stressor yang menyebabkan depresi. Salah satunya adalah dengan menggunakan musik. Musik dapat menghubungkan antara pikiran dan hati para penderita depresi sehingga mereka dapat membuka diri (Purbowinoto dan Kartinah, 2010). 


\section{METODE PENELITIAN}

Jenis penelitian ini adalah analitik pre experimental dengan menggunakan pendekatan metode one group pre post test design. One group pre post test design merupakan cara pengukuran terhadap satu kelompok tanpa adanya kelompok pembanding (kontrol) dengan melakukan satu kali pengukuran di depan (pre test) sebelum dikenai perlakuan tertentu. (Notoatmojo, 2012).

Sedangkan Populasi dalam penelitian ini adalah lansia yang mengalami depresi usia $60-74$ tahun berjumlah 40 lansia di UPTD Griya Werdha Jambangan Surabaya menggunakan teknik purpossive sampling dengan jumlah responden sebanyak 36. Variabel Independen yaitu Terapi Musik Keroncong dan Variabel Dependen yaitu Tingkat Depresi Pada Lansia danpengumpulan data menggunakan teknik studi lapangan dengan menggunkan instrument penelitian berupa kuesioner, lembar observasi.

\section{HASIL DAN PEMBAHASAN}

Hasil

1. Data Umum

Tabel 1. Distribusi Frekuensi responden $(\mathrm{n}=36)$

\begin{tabular}{|c|c|c|c|}
\hline Kate & & $\sum$ & $\%$ \\
\hline Jenis & elamin & & \\
\hline - & Perempuan & 19 & 52.8 \\
\hline - & Laki-laki & 17 & 47.2 \\
\hline Usia & & & \\
\hline - & $<59$ tahun & 1 & 2.8 \\
\hline - & 60-74 tahun & 28 & 77.8 \\
\hline- & $>74$ tahun & 7 & 19.4 \\
\hline Pend & ikan Terakhir & & \\
\hline & SD & 3 & 8.3 \\
\hline & SMP & 9 & 25.0 \\
\hline- & SMA & 19 & 52.8 \\
\hline - & Sarjana & 5 & 13.9 \\
\hline
\end{tabular}

(Sumber : Data Primer, 2020)

Berdasarkan tabel 1 menunjukkan bahwa responden jenis kelamin Perempuan sebesar 52,8\%, masuk kategori elderly (lanjut usia) sebesar 77,8\% dan berpendidikan SMA sebanyak 52,8\%.

2. Data Khusus

Tabel 2. Distribusi Frekuensi Tingkat depresi sebelum dan sesudah perlakuan

\begin{tabular}{lrrrr}
\hline \multirow{2}{*}{ Tingkat Depresi } & \multicolumn{2}{c}{ Sebelum } & \multicolumn{2}{c}{ Sesudah } \\
\cline { 2 - 5 } & $\sum$ & $\%$ & $\sum$ & $\%$ \\
\hline Normal & 5 & 13.9 & 12 & 33.3 \\
\hline Ringan & 11 & 30.6 & 16 & 44.4 \\
\hline Sedang & 10 & 27.8 & 7 & 19.4 \\
\hline Berat & 10 & 27.8 & 1 & 2.8 \\
\hline total & 36 & 100 & 36 & 100 \\
\hline
\end{tabular}

(Sumber : Data Primer, 2020)

Dari tabel 2 di atas menunjukkan bahwa sebelum diberikan perlakuan, responden mempunyai kecemasan berat sebesar 27,8 \% dan setelah diberikan perlakuan menjadi $33.3 \%$ tingkat depresi normal.

\section{Hasil Uji Statistik}

Tabel 3. Analisis Uji Wilcoxon

Wilcoxon Signed Ranks Test

\begin{tabular}{|c|c|}
\hline $\begin{array}{c}\text { Sebelum perlakuan-Sesudah } \\
\text { perlakuan }\end{array}$ & $\mathrm{N}$ \\
\hline Negative Ranks & 7 \\
\hline Positive Ranks & 28 \\
\hline Ties & 1 \\
\hline Total & 36 \\
\hline
\end{tabular}

1. Hasil uji statistik terdapat 36 responden yang mengalami tingkat depresi sebelum perlakuannormal sejumlah 5 orang, depresi ringan sejumlah 11 orang, depresi sedang sejumlah 10 orang, dan depresi berat sejumlah 10 orang.

2. Setelah diberi perlakuan menghasilkan 28 responden mengalami penurunan tingkat depresi sesudah perlakuan, 7 responden mengalami peningkatan sesudah perlakuan, dan 1 responden menglami tingkat depresi yang sama sebelum dan sesudah diberi perlakuan.

3. Hasil uji statistik wilcoxon diperoleh angka signifikan ( $\mathrm{p}$ value) atau $\mathrm{Z}$ hitung $(0,000)$ lebih rendah dari $\mathrm{Z}$ tabel 0,05 atau $(\mathrm{p}<\alpha)$, maka Ho ditolak dan H1 diterima yang berarti ada Perbedaan Tingkat Depresi pada Lansia Sebelum dan Sesudah Diberikan Terapi Musik Keroncong di UPTD Griya Werdha Jambangan Surabaya. 


\section{Pembahasan}

\section{Tingkat Depresi Lansia Sebelum DiberikanTerapi Musik Keroncong}

Berdasarkan tabel data khusus, menunjukkan bahwa responden yang memiliki tingkat depresi normal sejumlah 5 orang $(13,9 \%)$, ringan sejumlah 11 orang $(30,6 \%)$, sedang sejumlah 10 orang $(27,8 \%)$, dan berat sejumlah 10 orang $(27,8 \%)$.

Depresi dan lanjut usia merupakan tahap akhir siklus perkembangan manusia. Semua orang berharap akan menjalani hidup dengan tenang, damai, serta menikmati usia tua bersama anak, cucu, dan keluarganya. Pada kenyataannya, tidak semua lansia mendapatkan hal tersebut. Persoalan hidup yang biasa menimpa lanjut usia diantaranya, kemiskinan, kegagalan, kehilangan, konflik dengan keluarga atau anak, tidak memiliki keturunan yang merawatnya.Selain persoalan hidup tersebut, banyak perubahanperubahan lain yang lansia alami, seperti perubahan fisik, perubahan sosial, dan perubahan psikologis. Lansia yang mengalami perubahan tersebut akan mengalami berbagai macam perasaan sedih, cemas, kesepian, merasa tidak berharga, dan mudah tersinggung. Perasaan tersebut merupakan masalah gangguan kesehatan jiwa yang dialami lansia, salah satunya adalah depresi (Nursalam, 2013).

Hasil kuesioner responden yang mengalami depresi mengatakan bahwa mereka merasa sedih yang berkepanjangan, pesimisme, merasa gagal dan tidak puas pada dirinya sendiri, serta mengalami keletihan dan kehilangan nafsu makan, bahkan kadang muncul rasa ingin bunuh diri. Hal ini sesuai dengan 21 item pada kuesioner BDI (Beck Inventory Beck) yang menggambarkan kesedihan, pesimistik, perasaan gagal dan ketidakpuasan, rasa bersalah dan tidak menyukai diri sendiri, keinginan bunuh diri, menarik diri dari hubungan sosial, perubahan gambaran diri, pengambilan keputusan, insomnia, kelelahan, anoreksia, perasaan marah dan rasa tidak berharga. Tingkat Depresi Lansia Sesudah Diberikan Terapi Musik Keroncong.

\section{Tingkat Depresi Lansia Sesudah DiberikanTerapi Musik Keroncong}

Berdasarkan tabel data khusus sesudahdiberikan intervensi terapi musik keroncong pada lansia yang mengalami depresi adalah terjadi penurunan skor tingkat depresi padalansia. Hal ini sesuai dengan hasil kuesioneryang menunjukkan lansia dengan depresi berat mengalami penurunan tingkat depresi sebesar $25 \%$, depresi sedang sebesar $8,4 \%$, depresi ringan sebesar $3,8 \%$, dan normal sebesar $19,4 \%$. Penurunan tingkat depresi pada lansia dapat dipengaruhi oleh obat-obatan antidepresan yangbekerja dengan cara menormalkan neurotransmitter otak sehingga dapat mempengaruhi mood. Namun, obat-obatan tersebut dapat menimbulkan beberapa efek samping dan lansia yang sering kambuh memerlukan terapi perawatan dosis penuh dari sebelumnya.

Selain obat-obatan, penatalaksanaan untuk depresi bisa dilakukannya psikoterapi (talktherapy) oleh psikiater, ECT (Elektroconvulsi Therapy), dan pendekatan psikoanalisis yakni terapi musik.Manfaat terapi musik sendiri adalah membantu mengekspresikan perasaan, membantu rehabilitas fisik, memberi pengaruh positif pada suasana hati dan emosi, serta meringankan rasa sakit.

Terapi musik pertama kali diterapkan dan dikembangkan oleh Priestley di Eropa dan Amerika dengan menggunakan teori dari Sigmund Freud tentang tatanan struktural id, ego, dan superego. Musik disertai pertukaran verbal membantu menggali masalah-masalah klien dan memahami tentang dunianya, kebutuhannya, dan apa yang dirasakannya (Djohan,2006). Musik keroncong yang diberikan bertempo pelan sesuai dengan kesukaan para lansia.

Musik dengan tempo lamban memberikan rangsangan pada korteks serebri (korteks auditorius primer dan sekunder) yang diteruskan oleh FFR Frequency Following Response) sehingga dapat menyeimbangkan gelombang otak menuju gelombang otak alfa yang menandakan ketenangan (Herawati, 2019). Perubahan gelombang alfa akan menyebabkan peningkatan hormon serotonin (pengatur perubahan mood). Ketenangan yang ditimbulkan dari pemberian terapi musik membuat lansia nyaman dan rileks. Jadi, menurut peneliti perlu adanya tindakan efektif dengan efek samping minimalis untuk mengatasi tingkat depresi pada lansia, agar lansia 
dapat menikmati kehidupannya di usia senja dengan pikiran-pikiran yang positif.

Menurut Peneliti, terapi musik dengan tempo lamban hingga sedang dengan berbagai macam musik, seperti pop, jazz, keroncong, murrotal Al-Quran sangat efektif digunakan sebagai terapi untuk kesehatan.

\section{Perbedaan Tingkat Depresi pada Lansia Sebelum dan Sesudah Diberikan Terapi Musik}

Berdasarkan hasil penelitian dengan 36 responden, sampel yang digunakan adalah sampel kecil. Maka, pengujian hipotesis penelitian ini menggunakan uji beda rata-rata 2 sampel berpasangan non parametrik, yaitu uji Wilcoxcon yang diketahui bahwa $p$ value $0,000<\mathrm{p}$ tabel 0,05 , sehingga dapat diketahui ada perbedaan tingkat depresi pada lansia sebelum dan sesudah diberikan terapi musik keroncong di UPTD Griya Werdha Jambangan Surabaya.

Hal ini sejalan dengan penelitian sebelumnya yang menyatakan bahwa dengan menggunakan musik yang sederhana, menenangkan dan mempunyai tempo teratur dapat mengatasi depresi pada lansia.

Hasil perlakuan terapi musik keroncong menunjukkan bahwa 1 orang mengalami depresi berat $(2,8 \%)$, depresi sedang 7 orang $(19,4 \%)$, depresi ringan 16 orang $(44,4 \%)$, dan normal 12 orang $(33,3 \%)$. Analisis yang dilakukan adalah membandingkan hasil sebelum diberi perlakuan dan sesudah diberi perlakuan untuk semua responden tanpa adanya kelompok kontrol. Musik keroncong yang digunakan adalah lagu- lagu jaman dahulu, seperti Surabaya, Bengawan solo, dan Rayuan Pulau Kelapa yang dinyanyikan oleh Sundari Soekotjo dengan tempo pelan hingga sedang selama 30 menit seminggu 3 hari. Judul lagu tersebut merupakan lagu favorit para lansia yang terbukti ketika lagu-lagu tersebut diputar, sebagian lansia ikut menyanyikan. Terapi musik keroncong ini berfungsi untuk membantu mengekspresikan perasaan, membantu rehabilitas fisik, memberi pengaruh positif terhadap suasana hati dan dapat meningkatkan memori para lansia. Sehingga, dapat diharapkan dapat membantu mengatasi depresi, mencegah penyakit, dan meringankan rasa sakit (Djohan, 2006).

Menurut peneliti, terapi musik keroncong atau terapi musik genre lain dengan tempo lambat terbukti efektif untuk digunakan sebagai terapi menurunkan tingkat depresi pada lansia. Dibuktikan dalam penelitian ini dengan menggunakan musik sebagai terapi dapat meningkatkan atau memperbaiki kondisi fisik, emosi, kognitif dan sosial akan membantu menurunkan tingkat depresi pada lansia. (Nursalam, 2013)

\section{PENUTUP}

Ada perbedaan tingkat depresi pada lansia sebelum dan sesudah diberikan terapi musik keroncong. Untuk itu, terapi musik dapat menjadi pilihan untuk menurunkan skor depresi pada lansia di UPTD Griya Werdha Jambangan Surabaya

\section{DAFTAR PUSTAKA}

Abdul Muhith, S. S. (2016) Pendidikan Keperawatan Gerontik. Yogyakarta: CV AndiOffset.

Djohan. (2006). Terapi Musik, Teori, dan Aplikasi. Yogyakarta: Galangpress.

Herawati, N. (2019) Hubungan karakteristik dengan kejadian depresi pada lansia', 7, p. 2.

Irawan, H (2013) 'Gangguan depresi pada usia lanjut', pp. 815-819.

Livana et al. (2018) 'Gambaran Tingkat Depresi Lansia', NURSCOPE: Jurnal Keperawatan dan Pemikiran Ilmiah, 4(4), pp. 80-93.

Maryam, R. sit. (2008) Mengenal usia lanjut dan perawatannya. Jakarta: Salemba Medika.

Notoatmojo, S. (2012) Metodologi Penelitian Kesehatan. Jakarta: Rineka Cipta Remaja.

Nursalam (2013) Metodologi Penelitian Ilmu Keperawatan. Jakarta: Salemba Medika. 